\title{
Physicochemical study of a synthetic peptide belonging to human filaggrin protein
}

\author{
T. Pérez, M. Muñoz ${ }^{1}$, Y. Jaouher ${ }^{1}$, M.A. Alsina ${ }^{1}$ and I. Haro \\ Department of Peptide \& Protein Chemistry, IIQAB-CSIC, Jordi Girona 18-26, \\ 08034 Barcelona, Spain \\ ${ }^{1}$ Department of Physicochemistry, Faculty of Pharmacy, University of Barcelona, \\ Av. Joan XXIII, s/n, 08028 Barcelona, Spain
}

\begin{abstract}
In the present work the physicochemical characterization of the (306-324) synthetic peptide sequence from human filaggrin protein and its palmitoilated derivative was carried out.

Monomolecular layers of dipalmitoilphosphatidilcholine (DPPC) were used to study lipid/peptide interactions.

Measurements of surface activity, compression isotherms and DPPC miscibility are reported.
\end{abstract}

\section{INTRODUCTION}

Filament-aggregating protein (Filaggrin) is produced during the late stages of terminal differentiation of epithelial cells in mammals. Recently, several authors have found that antikeratin antibodies (AKA) and the antiperinuclear factor (APF) that are present in patients with rheumatoid arthritis, recognised human epidermal filaggrin and thus being called antifilaggrin autoantibodies $[1,2]$.

In the present work we describe and discuss the physicochemical characterization of the (306-324) synthetic peptide sequence and its palmitoil derivative belonging to human filaggrin protein in order to gain more insight into the interaction of antigenic peptides with biomembrane models.

\section{EXPERIMENTAL PART}

\subsection{Peptide Synthesis}

Filgg(306-324) peptide was synthesized manually on a Rink amide $(0.65 \mathrm{meq} / \mathrm{g})$ resin by solid-phase methodology following an Fmoc/tBut strategy and by means of a $N, N^{\prime}$-diisopropylcarbodiimide/1hidroxybenzotriazole (DIPCDI/HOBt) activation.

Palmitoil derivative was obtained also working in solid phase using palmitic acid and DIPCDI/HOBt coupling reagents in dimethylformamide/dichloromethane, as previously described for other synthetic peptides [3]. The peptides were synthesized as peptide amides. The identity of the peptides was confirmed by mass spectrometry.

\subsection{Physicochemical studies}

\subsubsection{Compression Isotherms}

Compression isotherms were performed on a Langmuir film balance equipped with a Wilhelmy platinum plate. The output of the pressure pickup was calibrated by recording the well-known isotherm of stearic acid. Peptide monolayers were spread on the surface. After spreading of the film, 10 minutes was allowed for solvent evaporation. Films were compressed at a speed of $80 \mathrm{~cm} / \mathrm{min}$. All isotherms were run at least four times in the direction of increasing pressure with freshly spread films. The accuracy of the system was $\pm 0.25 \mathrm{mN} / \mathrm{m}$. All measurements were made at a surface temperature of $21 \pm 1^{\circ} \mathrm{C}$. 


\section{RESULTS AND DISCUSSION}

Free Filgg(306-324) was not able to form stable monolayers (Fig.1). This result could be related with the high hydrophilicity of this underivatized peptide consequence of the great content on Arg residues. On the contrary the palmitoyl derivative of the above described peptide forms stable monolayers (Fig. 2) and thus the miscibility of the lipophillic derivative with a neutral lipid could be studied through compression isotherms of monolayers.
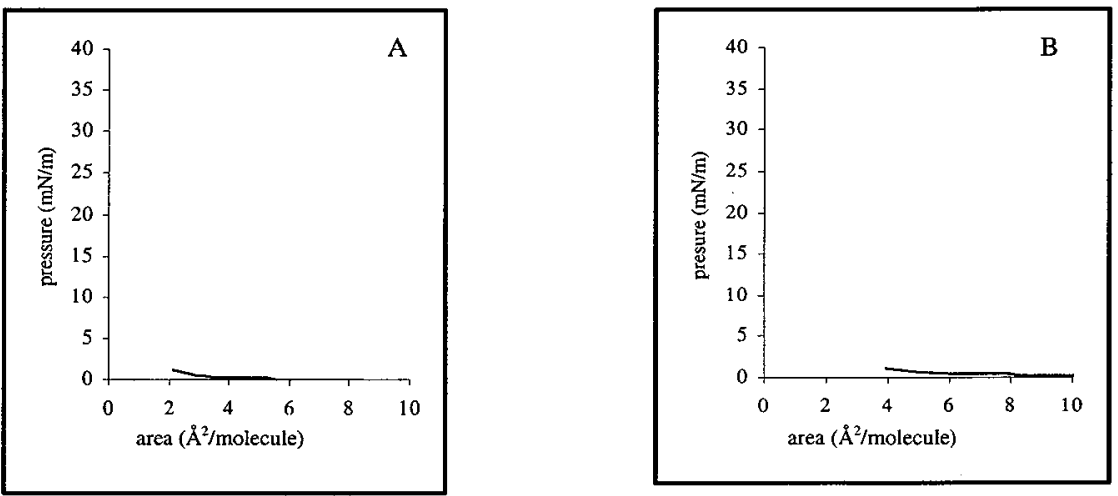

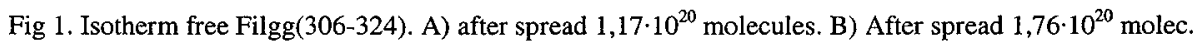

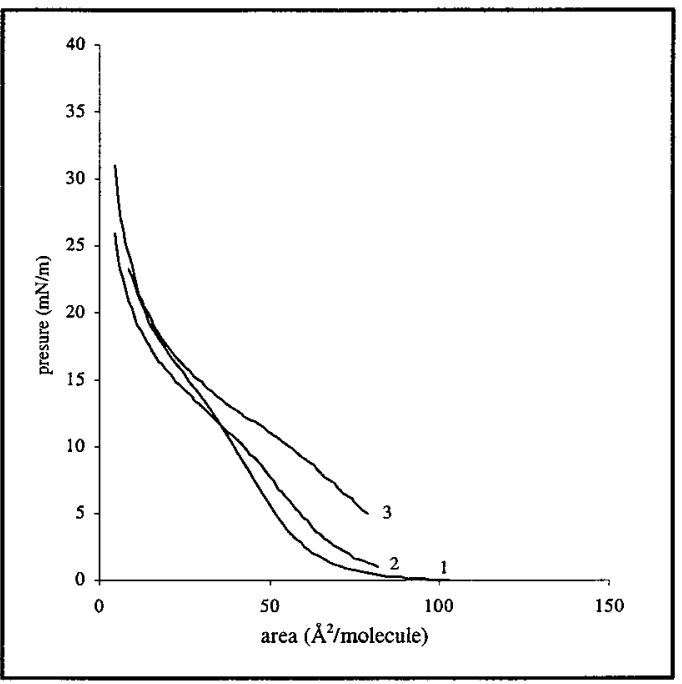

Fig. 2. Compression isotherms of palmitoyl derivate spread on PBS subphase. $1-2,63 \cdot 10^{19}$ molecules. $2-5,27 \cdot 10^{19}$ molecules. $3-7,91 \cdot 10^{19}$ molecules.

Fig. 3 shows the isotherms obtained when compressing pure films of dipalmitoilphosphatidylcholine (DPPC), Palm-Filgg(306-324) and mixtures of both. Mixed monolayers give curves intermediate to those of DPPC and peptide monolayers; the presence of increasing amounts of peptide eliminates the wellknown phase change of DPPC. 
Miscibility was also studied representing area versus monolayer composition at different surface pressures (Fig. 4). Due to the fact that collapse pressure was not achieved, we could not be able to conclude if the mixtures were completely miscibles [4].

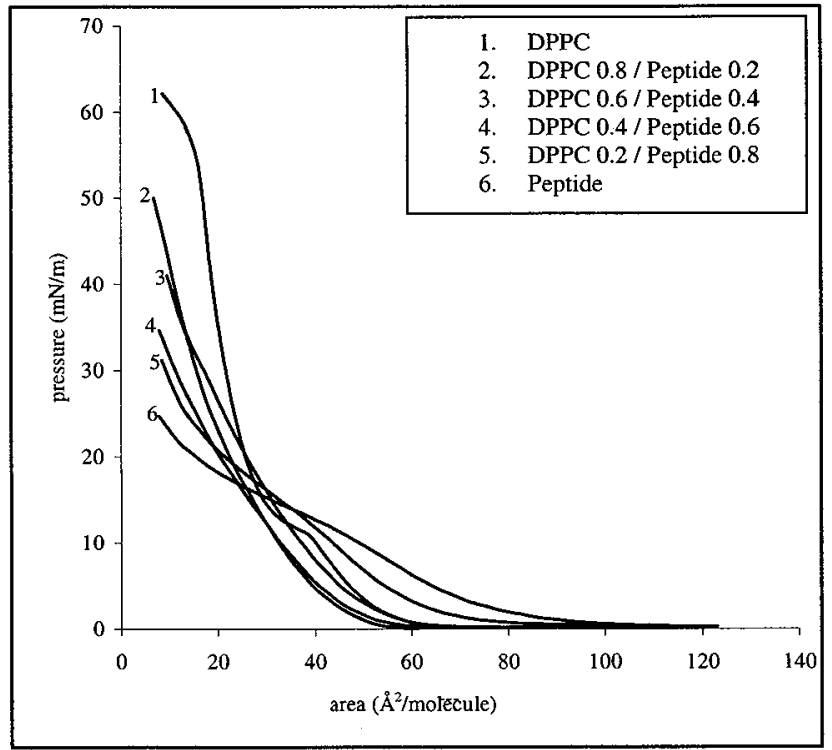

Fig 3. Compression isotherms of DPPC, Palm-Filgg(306-324) and mixtures of both spread on PBS subphase.

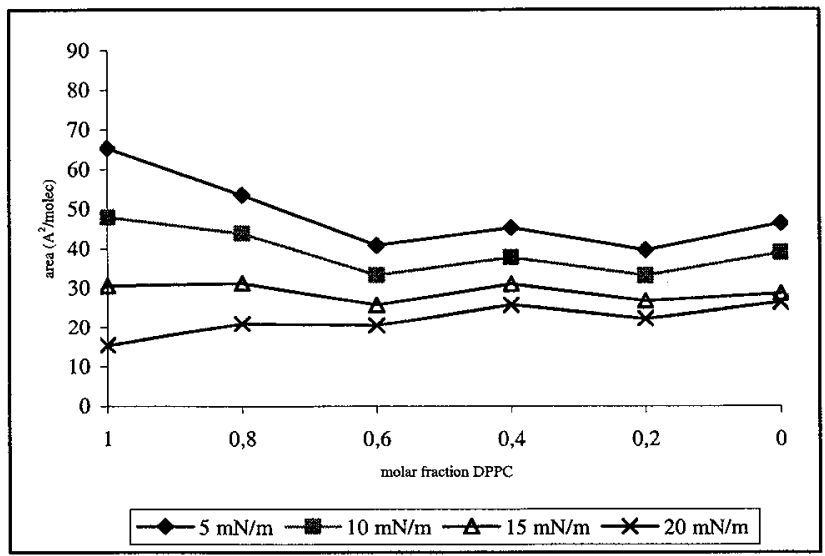

Fig. 4. Mean area per molecule versus monolayer composition for DPPC/ Palm-Filgg(306-324) compression isotherms measured at different surface pressures $(5,10,15$ and $20 \mathrm{mN} / \mathrm{m})$.

\section{REFERENCES}

[1] Simon, M. et al., J. Clin. Invest. 92, 1387-1393 (1993)

[2] Sebbag; M. et al., J. Clin. Invest. 95, 2672-2679 (1995)

[3] M. Garcia, M. Pujol, F. Reig, M.A. Alsina, I. Haro, Analyst 121, 1583-1588 (1996)

[4] Gaines, G.L. (1966). Insoluble Monolayers at liquid-gas interface. Interscience Publishers. 